\title{
Veinte años después: Hablan los actores de los Acuerdos de Paz
}

Mario Aguiñada CarRanZa

RESUMEN: El presente trabajo es un fragmento de un libro inédito sobre los Acuerdos de Paz. En él, se recogen los testimonios de primera mano de los actores políticos involucrados en el proceso de paz. Este trabajo permite apreciar la complejidad de este proceso, en el cual, además del gobierno y el FMLN, jugaron un papel importante las organizaciones de la sociedad civil, el empresariado y los partidos políticos.

ABSTRACT: The following paper is a fragment of an unpublished book about the Peace Agreements in El Salvador. It counts with the testimonies of the political actors involved in the peace process. This paper makes possible to appreciate the complexity of the process in which, besides the government and the FMLN, the civilian society, the entrepreneurial sector and the political parties played an important role. 

de la firma de los Acuerdos de Paz y éstos ya han sido cumplidos satisfactoriamente. Resulta de especial significación conocer las opiniones de los protagonistas sobre diversos aspectos y acontecimientos del proceso de paz.

A ese efecto, se realizaron entrevistas con 50 personas que jugaron papeles relevantes en diversos momentos de ese período, ya sea representando al gobierno, al FMLN, a los partidos políticos, a la iglesia, a la empresa privada o a la Asamblea Legislativa; para hacer un examen objetivo, que nos permitiera aproximarnos a una visión de conjunto sobre lo que se ha logrado y lo mucho que queda por hacer; cuando ya pasaron los temores, la inseguridad, los tropiezos y desconfianza inmediatos a la firma de la paz, y nos beneficiamos del renacimiento de una forma de vida social nueva en condiciones de paz, tolerancia y avances democráticos.

La voluntad de dialogar y la búsqueda de una solución política negociada al conflicto se expresó todavía tímidamente en la primera mitad de la década de los años 80 , con las iniciativas de los obispos salvadoreños, del gobierno de unidad nacional, y más fuertemente con las gestiones del Grupo Contadora; pero cobró el carácter de proceso factible a partir de la reunión realizada en La Palma, Chalatenango, el 15 de octubre de

1984, entre delegados del FMLN y del Gobierno de la República, con la presencia del Presidente José Napoleón Duarte.

A partir de ese momento se produjeron coincidencias y desavenencias, acuerdos puntuales, conflictos y prolongados estancamientos, pero al final después de ocho años transcurridos desde la primera ofensiva militar del FMLN iniciada el 10 de Enero de 1981, los salvadoreños entendimos que teníamos un imperativo con el presente y el futuro del país: terminar la guerra y construir la paz, responsabilidad que todos debíamos compartir y así, se hizo más fácil y menos largo el camino.

De esos problemas y momentos hablan nuestros entrevistados; quienes tienen diferentes formas de pensar y de ver las cosas, pero todos están absolutamente convencidos de que trabajar por la paz es lo mejor que ellos han podido hacer en su vida y por el país; aunque no hayamos sido capaces aún de encontrar un proyecto común de desarrollo integral que prepare a El Salvador como nación ante los grandes retos de la pobreza, el desarrollo humano de los ciudadanos, la sostenibilidad del país y la competencia en el mundo globalizado de hoy.

La presentación de las entrevistas se hace simulando un debate sobre un mismo tema propuesto por el autor de este estudio, lo que permite apreciar la riqueza de 
las opiniones, las coincidencias y desavenencias y mostrar la verdad entre las verdades parciales de cada uno de los entrevistados.

Los temas en que están ordenadas las entrevistas son:

1. Contexto y alcances de las Iniciativas de Diálogo del Presidente José Napoleón Duarte.

2. Factores internos y externos que propiciaron las negociaciones.

3. El papel de la Asamblea Legislativa y de los Partidos Políticos.

4. La sociedad civil empujó hacia la Paz.

5. Despertar y presencia del empresariado salvadoreño.
6. Personajes que trabajaron por la paz.

En ellos las opiniones se presentan como fueron dichas por sus autores, espontáneamente, con vehemencia y convencimiento. Por eso hemos prescindido de hacer comentarios o conclusiones sobre las mismas. ${ }^{1}$

La invitación a participar en esta investigación se extendió a un número mayor de las personas que fueron entrevistadas, incluyendo a funcionarios de las Naciones Unidas que tuvieron activa participación y responsabilidad en nuestro proceso de paz, pero no fue posible recibir su cooperación, por las múltiples ocupaciones de dichas personas, sin embargo, a ellas también expresamos nuestro reconocimiento.

\section{Contexto y alcances de las iniciativas de diálogo del presidente Napoleón Duarte}

En su discurso en la 39 Asamblea General de la Organización de las Naciones Unidas, el 8 de Octubre de 1984, el Presidente de la República José Napoleón Duarte en forma sorpresiva y sin tomar ninguna providencia preparatoria, invitó públicamente al Frente Democrático Revolucionario (FDR), y al Frente Farabundo Martí para la Liberación Nacional (FMLN), a realizar una primera reunión de diálogo para buscar el cese del enfrentamiento armado el 15 de Octubre de ese mismo mes, en el municipio de La Palma, Departamento de Chalatenango, situado en una de las zonas de mayor persistencia guerrillera. La reunión se realizó, luego que la Ilamada Alianza Democrática Revolucionaria respondiera afirmativamente e involucrara a varios gobiernos de Centro y Suramérica, y a la Cruz Roja Internacional para que acompañaran ese acontecimiento.

Sobre este hecho, el contexto en que se dio y los alcances que 
tuvo, se interrogó a nuestros entrevistados, quienes desde su propia experiencia, la ubicación política en que se encontraban y el análisis no siempre desinteresado y desde su propio prisma, han enriquecido la visión que sobre esas iniciativas han trascendido a la opinión pública.

\section{DAGOBERTO GUTIÉRREZ LINARES}

"Yo no sé si Duarte quería negociar, es muy difícil saberlo, pero sí creo saber que no podía negociar, porque él no tenía el poder para hacerlo y además porque la lógica de su gobierno era la de la contrainsurgencia cuya esencia era la de la solución militar del conflicto; tampoco Duarte podía negociar, porque la cabeza de Washington y la cabeza de la fuerza armada estaban al servicio de una victoria militar y el diálogo que se dio en esos años, era un diálogo contrainsurgente. No siempre un diálogo ni una negociación están al servicio de una solución política. Es viable pensar en un diálogo y una negociación al servicio de una victoria militar. Por eso, durante los contactos con Duarte siempre aparecía la figura de la rendición como requisito para dialogar y uno puede pensar que esa era una locura, pero no, es que esa era la lógica del momento y Duarte no podía darle vuelta a esa lógica, por eso digo que no sé si él quería negociar, pero sí sé que él no podía negociar.
Todo estaba montado sobre el riel de vencer en el frente de batalla y el diálogo que se daba en ese momento estaba al servicio de esa victoria militar; ahora bien, ¿qué pasa con Cristiani? ¿Quería negociar?, no; ARENA, ¿quería negociar?, no; la Fuerza Armada ¿quería negociar?, no. Conociendo uno la cabeza de la oligarquía salvadoreña primitiva y montaraz, viva para hacer dinero pero liberada de la inteligencia que supone siempre un horizonte, uno puede pensar que la solución negociada de una guerra que era y sigue siendo una cosa infamante para la psicología de esta gente, que una parte del pueblo se alzara en armas, que resistieron durante doce años y que no se pudiera colgar a esos insurgentes como se había hecho en 1932 era una cosa muy grave para que el camino de la negociación se abriera paso en la cabeza de esta gente.

Ahora, ¿tenía Cristiani el poder para negociar?; sí, ¿tenía más poder que Duarte? Por supuesto que sí".

\section{JORGE ALBERTO VILLACORTA}

"El PDC con Napoleón Duarte a la cabeza nunca asumió la solución negociada como una salida, creo que menos desde el área del otro contendiente. Estoy convencido que para Napoleón ganar militarmente era no sólo fácil, lógico, necesario, sino que indispensable y los gringos se dieron cuenta de que 
se podía, entonces mientras se tuvo esa concepción y mientras participamos en los diálogos con Napoleón siempre encontré eso, ofrecer perdón y olvido que reflejaban ese pensamiento.

Yo no percibía que el PDC lo asumiera e hiciera lo que creo que en el FDR hacíamos, un permanente debate por la solución política negociada y nuestra insistencia en eso; no niego que la otra dinámica era lo suficiente como para ganar en medio de la guerra y cuando uno está en eso, obviamente quiere ganar. Creo que es el gran éxito. Dijeron: "vamos a institucionalizar esto en medio de la guerra, y a partir de ahí vamos a hacer la Constitución". Creo que eso fue el gran éxito de Napoleón y su proyecto, éxito que nosotros, del otro lado, nunca pudimos revertir, lo llegamos a cuestionar, lo llegamos a dificultar; pero ahí nos ganaron el punto porque desde el instante que ellos instalaron ese proceso de institucionalización, fueron dando los pasos uno tras otro, de la constituyente en adelante no hay duda.

Pero, ¿eso era suficiente para tener una solución política negociada? Yo creo que no, era un instrumento que formaba parte de la misma concepción de la guerra de ganar militarmente; esa institucionalidad servía evidentemente para darle toda la base y el apoyo a la guerra. Y la frase de Napoleón de "perdón y olvido", es porque en ese momento consideraba que militarmente había ganado".

\section{JOSE ANTONIO MORALES EHRLICH}

“En la época de Duarte era bien remota la posibilidad de alcanzar la paz. Recuerdo que una vez, hablando con Ellacuría, él me decía que el FMLN todavía no había tomado la decisión de hacer la paz, que el diálogo era algo importante, pero no lo principal; que el FMLN le iba a sacar todo el provecho posible al diálogo, publicitario, internacional, etc., pero que no habían Ilegado a la decisión de hacer la paz y así vimos que se fueron discurriendo todas las reuniones y pasaba el tiempo.

Al principio, el FMLN estaba seguro de ganar la guerra y los militares también. Es más, había mesianismo y determinismo, sustentados en el razonamiento de que las cosas tenían que ser de tal forma y no podían ser de otra, eran las leyes de la historia.

Yo creo que tuvo bastante significado el diálogo en La Palma, porque más que todo era una acción de cambio, pero donde llegaba la parte militar, ahí surgían las dificultades; sin embargo, ya en Ayagualo la posición de Facundo Guardado ya era un cambio radical. Ahí apareció como heroico; al principio era de un gran entendimiento porque en muchas cosas había bastante afinidad entre el FMLN y nosotros; 
no había muchas diferencias con los cambios, pero lo que molestaba era la parte de la guerra, la parte militar que en el análisis del Frente pesó mucho ya para la reunión de Ayagualo donde las cosas estaban más hostiles; después se empezó a ver quién le sacaba más beneficio al diálogo, se asistía sabiendo que no se iba a lograr nada".

\section{OVIDIO HERNÁNDEZ}

"Con la propuesta de dialogar en La Palma, en octubre de 1984, la audacia de Napoleón Duarte sorprendió a todo mundo, planteando la apertura de pláticas y de inmediato contó con el beneplácito de la comunidad internacional y en particular de las Naciones Unidas; la cual desde ahí se interesó en retomar este proceso, que luego se dio en Ayagualo y en la Nunciatura, que si bien no fueron felices en concluir en algo, si fueron oportunas y propiciaron un acercamiento.

Napoleón era un hombre de dos rasgos: de impulsos y un hombre difícil; Napoleón funcionaba mejor en crisis que en una situación normal. En crisis, se la jugaba todas, era lúcido y audaz y tenía valor para impulsar lo que pensaba. Ese era su estilo, por eso a mí no me extraña que se le haya ocurrido proponer el diálogo en La Palma, al dar el discurso en Nueva York en el marco de la Asamblea General de las Naciones Unidas. No me cabe la menor duda que así fue.
También él mentía calculadamente y a propósito de los mediadores que nombró, los Monseñores Arturo Rivera y Damas y Gregorio Rosa Chávez, pensó hablarles, pero no lo hizo oportunamente, eso es muy probable, o sea que sí se necesita haber conocido a Napoleón. Yo era el que más discutía con él y tanto es así que, en dos intentos de aspirar a la presidencia, no lo acompañé, estuve en el bando contrario; no porque no le tuviera cariño, no porque dudara de su autenticidad, sino porque yo creía que no era el momento y que yo lo quería, como le dije una vez, tirador de tiros largos no de tiros cortos. Haberse metido a la Junta de Gobierno no era de mi parecer, le dije que esperara se agotara ese esquema y que entonces se lanzara de candidato a la presidencia, pero en fin digo, había que conocerlo ya en la intimidad. Desde niño pudo haber dicho yo voy a ser Presidente de El Salvador, y eso creo que lo marcó para toda su vida.

Cuando estuvo en la Junta de Gobierno, Napoleón siempre fue de la idea de propiciar elecciones lo más pronto posible. Por eso, a principios de la década de los 80 , promueve un gobierno de transición, es el de Álvaro Magaña y se firma el Pacto de Apaneca e impulsa la convocatoria de la Asamblea Constituyente, porque él siempre tuvo en mente una salida que volviera a la constitucionalidad. Napoleón, comprendámoslo, fue un personaje discutido, conflictivo, pero al fin 
y al cabo marcó una pauta democrática, por eso yo no me atrevería a criticarlo".

\section{ABRAHAM RODRÍGUEZ}

“Napoleón no podía conseguir la paz, no lo permitía la derecha que tenía la tesis de que él quería entregarle el país a la izquierda, que no quería ganar la guerra, que salvaba a los guerrilleros cuando estaban encerrados por el ejército en las montañas; era imposible que Napoleón pudiera conseguir esa paz, no había condiciones. En cambio, Cristiani sí, porque era cabalmente la derecha la gente que confiaba en él.

El Gobierno de Napoleón era completamente inviable porque para llegar a negociar una paz con el FMLN debía tener el acuerdo de la Fuerza Armada y esta se encontraba empeñada en un triunfo militar; no olvidemos que el fenómeno de la paz era primero de la derecha, pero ocurrieron acontecimientos históricos importantes, la ofensiva de noviembre de 1989 en donde el ejército comprendió que realmente la guerrilla era una fuerza militar de consideración".

\section{MILENA CALDERÓN DE ESCALON}

"El diálogo de Duarte fue un diálogo de show político. El país vivía momentos difíciles con una crisis económica grande, entonces él tenía que hacer algo, pero que en el fondo él no estaba muy convencido, era para sacarle raja política.

En ese momento el Partido Demócrata Cristiano creía que ellos estaban en el clímax de poder, sentían que cualquier esfuerzo de diálogo era parte de su éxito, de hacer politiquería más que de convencimiento por la paz; en ese sentido ARENA juega otro papel, porque cuando entra Cristiani nuestro objetivo y lo dijo Roberto D'aubuisson, que nuestro lema era alcanzar la paz".

\section{RUBÉN ZAMORA RIVAS}

"La evaluación que yo pueda hacer de Napoleón Duarte es muy problemática porque la relación personal era muy fuerte, la relación política también y nos confrontamos dentro del Partido Demócrata Cristiano. Ahora viéndolo en perspectiva, creo que en el proceso nuestro hay que hacer como en la Biblia, una separación bastante clara entre el Viejo Testamento y el Nuevo Testamento; porque lo que hace la separación de la Biblia es el nacimiento de Cristo. En el caso nuestro lo que hace la separación es la ofensiva de noviembre de 1989, eso es, pero hay un Viejo Testamento que es distinto del Nuevo, si pero el Viejo Testamento es la perspectiva cristiana, anuncia el Nuevo Testamento.

Entonces a Duarte yo lo veo ahora en esa perspectiva, o sea des- 
de el marco del Viejo Testamento, que era el marco de que había que derrotar al otro no por la aniquilación de su fuerza física, sino por su disolución, y que en el otro caso, era derrotar al enemigo en batalla campal y todos decían que el FMLN nunca iba ganar en batalla campal pero si por un proceso insurreccional; ese era el marco dijeramos, en el que se ubica Duarte y por eso es que la oferta de él tiene un presupuesto mesiánico: yo soy la democracia, aquí hay democracia, vengan a participar a la democracia; la oferta nuestra en aquella época era exactamente paralela: nosotros somos la democracia, ustedes son la dictadura, rompan con los gringos, rompan con el ejercito, vamos a depurar la Fuerza Armada y vamos a integrarlo al nuevo ejército popular o lo que fuera.

Esas eran las primeras y originales propuestas que hicimos; eran inviables todas esas propuestas, tanto la de Napoleón como la nuestra; eran totalmente inviables, pero tenían un valor importante, que empezaron a crear condiciones ideológicas a favor de la negociación, que para mi eso es lo importante; o sea, La Palma, Ayagualo legitiman el llamamiento a la solución política; no era la solución política, propuesta por parte de él o de nosotros, yo creo que era un intento de decir: "mirá, venite conmigo, porque sólo aquí puede haber la verdad", pero sí tuvo un efecto muy positivo de cara a la población decir: "señores, aquí se puede de otra manera"; yo creo que ese es el gran valor que hay que reconocerle a Napoleon Duarte. En ese momento rompía esquemas, acuérdese también que del lado del FMLN-FDR nos tocó exactamente lo mismo y en un momento nosotros aceptábamos y fuimos defensores de la tesis de la depuración de la Fuerza Armada y de la incorporación al nuevo ejército popular de aquellos oficiales que no estuvieran manchados por la represión.

Por eso, para mí la figura del Viejo Testamento y el Nuevo Testamento, es útil, porque permite establecer una diferencia fundamental: Duarte no negoció, Cristiani sí lo hizo, pero Duarte y sus intentos crearon las condiciones ideológicas y sociales que luego le permitieron a Cristiani poder negociar. Por eso, no se puede decir que no valió de nada, es un error, pero también sostener que hay una continuidad como quien dice que queda una rampa, es otro error, hay un quiebre en esa rampa que para mi es noviembre.

Yo vería como dos puntos ahí. Primero, para mí, el discurso y los planteamientos de Cristiani en el 89 hasta noviembre, son del Antiguo Testamento. Yo recuerdo en esa época haber conversado dos o tres veces con él, cuando nosotros ya habíamos regresado al país, y para mí la suya siempre era la misma concepción de Duarte: "hay que detener a estos muchachos porque 
mucho molestan, no me dejan lograr el desarrollo del país que quiero, mientras haya guerra aquí va a estar fregado, que nos den un chance, que vengan y que no molesten"; esa era la concepción de Duarte también. Fredy lo ponía más en términos económicos, Duarte lo lo hacía más en términos políticos; Duarte hablaba más de la democracia y Fredy planteaba que era una necesidad de desarrollo. Por eso, para mí, de nuevo lo digo, en la ofensiva de noviembre se da el momento del camino de la paz para la izquierda y para la derecha".

\section{NIDIA DÍAZ}

"El PDC pudo hacer mucho más, desde el mismo año 79 que Duarte regresa al país de su exilio en Venezuela, pudo haber enrumbado un poco más su liderazgo y las bases de oposición que había en el país, las cuales eran bastante grandes y sin embargo, hubo un baño de sangre que abarcó internamente a la Democracia Cristiana.

Duarte apenas se sentó en La Palma, se comportó en forma prepotente, nos entregó la Constitución. una edición chiquita y de color azul, que yo creí que era el pasaporte, y dijo: "yo les pido que se acojan a esto"; entonces nosotros dijimos, "lo que hay que discutir es cómo se originó esta guerra y cómo la vamos a terminar, no venimos aquí a acogernos a nada".

$Y$ si se recuerda en el segundo diálogo de Ayagualo, hicimos una propuesta para humanizar el conflicto, otra para ver como se implementarían las reformas constitucionales elementales y él en sólo diez minutos la rechazó públicamente sin haber hecho ningún tipo de análisis. Es decir, ahí se evidenció que él no quería una salida de entendimiento".

\section{Factores internos y externos que propiciaron las negociaciones}

"Duarte dialogó, pero Cristiani negoció", es una frase que se escuchaba repetidamente en distintos rumbos y lugares hace unos siete años; con ella se pretendía obtener el reconocimiento público al partido de turno en el gobierno y censurar al partido del Presidente Duarte. De nuestra parte, quisimos indagar atrás de las apariencias o de la expresión externa del fenómeno, para descubrir las razones y causas que permitieron al Presidente Cristiani negociar y firma la paz, no sólo dialogar como lo hizo su antecesor y como él mismo lo propuso el $1^{\circ}$ de Junio de 1989, al asumir el mando presidencial.

En tanto la guerra era un fenómeno político-social objetivo que tuvo sus causas de carácter interno 
y externo, que le dieron origen, su solución por la vía pacífica también debía ser auspiciada por factores internos y externos de distinto signo, que apostarían a ponerle fin al conflicto bélico, por cuanto las condiciones regionales y mundiales habían cambiado sustancialmente doce años después de haberse iniciado el enfrentamiento armado.

Esta relación dinámica de causas y factores que propiciaron la paz, es analizada por nuestros entrevistados, que descubren la relación de dependencia de nuestro pequeño país con respecto a Estados Unidos y las grandes fuerzas internacionales, pero ponderan de una manera convincente la fuerza de los factores internos que contribuyeron a alcanzar la paz, para resolver nuestros problemas y ofrecernos como ejemplo para todas las naciones.

\section{DAGOBERTO GUTIÉRREZ}

"Entre los factores que contribuyeron a arribar a la solución política del conflicto, identifico al menos los siguientes: Primero, la lógica del capital, que no entiende más política que su negocio y si en función de su negocio, de su inversión y de su ganancia, parte del capital salvadoreño concluyó que terminar la guerra en el país era una cosa necesaria, y había llegado ese momento para hacerlo. Segundo, la realidad mostrada en el campo de batalla: los acontecimientos de 1989, la exi- tosa ofensiva militar que desatamos en noviembre de ese año, demostró que no era viable una solución militar. Tercero, la presión de Washington, porque a ellos se les habían caído sus castillos teóricos en el sentido que la guerra nuestra era un escenario del "conflicto entre el bien y el mal", y no era rentable continuar con este conflicto, había que terminar esta guerra de baja intensidad para pasar a montar en el país una democracia de baja intensidad y ensayar una forma nueva de resolver esta guerra; y cuarto, los cambios en toda la correlación de fuerzas internacionales. Me refiero específicamente al derrumbe del sistema del socialismo real, a los cambios y a las crisis de la Unión Soviética y Europa Oriental, que tienen una trascendencia bastante permanente y cuyos efectos duran hasta nuestros días y sin duda durarán muchos más años.

Llegó el momento de resolver la guerra y quien estaba en el gobierno era Cristiani. Es imprescindible señalar la relación dialéctica que existe entre la guerra y la negociación; en esa relación, la guerra es la madre de la negociación y esta segunda es un resultado inevitable que a su vez terminó con la guerra. Esta, a mi juicio, es una verdad inmensa, tomando en cuenta que en nuestro país y en nuestra sociedad no hay ni ha habido nunca, ninguna tendencia, corriente o pensamiento político orientado a resolver los conflictos por la vía de la negocia- 
ción; jamás ha sido así al menos que yo sepa.

Por eso, los acuerdos de Chapultepec constituyen una cosa rara en nuestra historia, y sólo se explica a la luz de los doce años de guerra que proporcionaron la fuerza militar y la fuerza política para sentar en la misma mesa de negociación a los insurgentes, a los jefes militares y al partido de gobierno de ese momento, que representaba a la derecha política y solo en cierto modo a la derecha social.

Ahora bien, resolver políticamente el conflicto implicaba en nuestro país más de una cosa: persuadir a los militares de que había que resolver políticamente el conflicto, habida cuenta de que la guerra era para una parte del capital y para la misma Fuerza Armada un importante negocio, porque Estados Unidos destinaba a este conflicto millones y millones de dólares y esos recursos no se veían en el frente de batalla; por eso nosotros, que no teníamos ese torrente de recursos, íbamos ganando en el terreno militar frente al adversario que sí lo tenía, para el cual el fin de la guerra significaba la conclusión de sus ingresos extraordinarios.

Es igualmente importante incorporar esa reflexión, porque cuando el mundo cambiaba y dejaba de ser un mundo bipolar y tendía a convertirse en un mundo unipolar y pluricentrista, el poder de Wash- ington era representado por su puño y para Centroamérica era un puño muy fuerte, grueso, armado, pero además muy cercano; pareciera ser que no era el momento oportuno para que la región se aglutinara ante Washington, pero sí era el momento oportuno y lo sigue siendo para que la región se aglutine ante la región misma; por cierto esto es una cosa que sigue siendo necesaria y cuando uno mira, oye o lee esfuerzos de integración, siempre conviene reflexionar sobre quién integra a quién, porque los países centroamericanos debemos establecer principios de relación políticos y económicos satisfactorios.

Ahora bien, siempre en el caso nuestro, el factor decisivo para terminar la guerra de manera negociada, lo constituyó el ejército guerrillero y el ejército gubernamental y las fuerzas de derecha, sociales y políticas"

\section{JOSE ANTONIO MORALES EHRLICH}

"Se nota un cambio en el ritmo y la contundencia de la guerra, a partir de la caída del Muro de Berlín. El derrumbe de la economía socialista significó que el FMLN iba a perder bastante de su respaldo internacional, podría pelear, yo diría unos cinco años más, tenía que pelear fuerte, pero estaba en un callejón sin salida e hizo lo que tenía que hacer, negociar, cuando todavía tenía fuerzas. Esto lo corro- 
bora con claridad meridiana el caso de Guatemala cuando negocian los insurgentes ya sin fuerza y ni el Presidente Álvaro Arzú quiere cumplir los Acuerdos que él mismo pactó; por el otro lado, los gringos salidos del peligro de que el comunismo se les metiera por Centroamérica también presionaron a los militares para que aceptaran negociar porque les salían caros; entonces, ambos grupos militares estaban ya presionados nacional e internacionalmente a buscar la paz.

En ese momento, el Presidente Cristiani, quien antes no había dado muestras de su vocación por la paz fue lo suficientemente hábil y ágil para darse vuelta y después convertirse en el Presidente de la Paz, no obstante que cuando en Septiembre de 1991 fue a Nueva York todavía estaba cerrado, pero le hicieron ver las cosas y empezó el cambio; un factor decisivo lo constituyó el hecho de que los militares creían ideológicamente en Cristiani; siendo él de la oligarquía económica ellos sabían que no los iban a fregar le tenían fe, porque todos eran de derecha y conservadores. En cambio, si Fidel Chávez hubiera ganado las elecciones, no se hubiera podido negociar la paz porque el capital se hubiera unido con los militares, para oponerse, por falta de confianza ideológica; le hubiera costado mucho más negociar, o le daban golpe de estado".

\section{JOSÉ RAFAEL MACHUCA}

"Realmente, lo que era fácil para todos era la lucha militar, los efectos políticos no eran tangibles por la misma violencia de la guerra, entonces la población, o lo que la generalidad veía, eran los muertos, los destrozos, los desastres, los daños; la parte psicológica no se podía valorar, porque la dinámica de la guerra era muy alta.

Aquí cada uno tomó posiciones. Era muy fácil pensar que los partidos de derecha, confiaban en que el Ejército tuviera posibilidad de éxito; pero cuando se da una lucha entre iguales, quizás unos con mejor equipo que otros, podía suponerse que la solución militar no era posible; sin embargo para los grupos que no estaban identificados con el gobierno, su opción más que militar era una respuesta política. Por otro lado, la población no tenía interés en favorecer a nadie, lo que dio como resultado que prácticamente la lucha armada estaba aislada y que una victoria militar de cualquiera de las dos partes era muy difícil, y el momento para buscar una solución no militar se fue generando paulatinamente, a medida que se iban viendo las condiciones reales del país y de la lucha entre las partes.

Asimismo, al principio se pensaba que la lucha se podía ganar 
militarmente por cualquiera de los bandos, pero en la medida que ésta se prolongó y la situación general se complicaba los países que estuvieron involucrados en eso, en un inicio, al final no quisieron seguir ayudando a ninguna de las partes para que ganara militarmente. En el entendido que la solución militar no iba a resolver las problemas reales del país, concretamente los problemas socioeconómicos que arrastrábamos desde mucho tiempo atrás.

Pero para mí las señales más claras de que se estaba cambiando la tesis de lo político por lo militar, aparecieron cuando se incorporan los partidos; porque nosotros realmente no teníamos ninguna capacidad militar. Éramos básicamente un grupo de ciudadanos nacionales, que no tenían apoyos mal intencionados de carácter internacional, en el buen sentido de la palabra, para poder incidir a favor de la solución política al conflicto.

Para mí, ese momento es muy fácil de establecer, sería en noviembre del año de 1989 cuando los del FMLN en el marco de la ofensiva militar aprietan en el Hotel El Salvador, donde estaba hospedado el Secretario General de la OEA, Señor João Baena Suárez y militares de Estados Unidos y entonces se terminaron de alguna manera las resistencias.

El caso salvadoreño fue diferente al caso de Nicaragua y al de
Guatemala, porque se cumplieron los acuerdos; el papel determinante para que se diera ese factor, desde mi óptica, fue la participación y el compromiso de las fuerzas políticas de realizar lo que se había decidido; había compromiso consciente de formalizar o de legalizar la parte, los acuerdos de paz acordados entre la guerrilla y el gobierno".

\section{MAURICIO ERNESTO VARGAS}

"En función de la realidad, un grupo de oficiales de la Fuerza Armada durante la primera mitad de la década de los años 80, estudiamos la situación del conflicto y las perspectivas de solución que podía tener. Se tuvo contacto diario con la población, pudimos llegar a lugares remotos a los que nunca habíamos llegado, donde la miseria y la pobreza eran latentes. Pudimos ver la muerte de civiles, de militares y de guerrilleros todos los días, ese sangramiento permanente. El estudiar evidentemente el conflicto y determinar que esto no era fácil desarrollarlo, ni tener un final militar, sino político; ese grupo no éramos generación de mando y no podíamos tomar decisiones pero se sentaron las bases a partir de ese estudio en el cual Duarte lo avaló y ahí comenzó a caminar en la ruta del diálogo.

Habían transcurrido casi cinco años, hasta que Ilegamos al Convento de las Hermanas Clarisas, en San Isidro Coronado, Costa Rica, en 
los meses de septiembre y octubre de 1989, en esa mesa estaban por el Gobierno: Rafael Hernán Contreras, Abelardo Torres, Juan Antonio Martínez Varela, Óscar Santamaría y David Escobar Galindo, y como asesores estuvimos: el General Dionisio Ismael Machuca y yo, el Dr. Francisco José Guerrero (Chachi Guerrero), Abraham Rodríguez y Roberto Murray Meza.

Aquí se ha dicho muy poco que el FMLN se vio forzado a suscribir el acuerdo de Derechos Humanos porque el Gobierno y la Fuerza Armada presentaron los 13 puntos de la Reforma de la Fuerza Armada; ellos nunca creyeron que se iba a discutir eso en la mesa de negociación, mucho menos que iba a ver una propuesta formal. Habíamos estado discutiendo creo que 15 días y en el último día, desde las 8:00 a.m. hasta las 5:00 de la madrugada del otro, construimos un Acuerdo de Derechos Humanos que ni habíamos hablado de él, pero había que salir de ese atolladero donde nos habíamos metido.

En El Salvador se logró la reconstrucción de la voluntad nacional de paz, lo que no existió en Nicaragua, lo que no ocurrió en Guatemala y lo que no existe en Colombia, ni en Perú o lo que no existe en Filipinas.

En ese sentido, podemos decir que estos son los dos elementos que permitieron hacer lo que se hizo y adicionalmente nosotros sí entramos a la fase de transición del conflicto a la paz; las transiciones en términos teóricos quiere decir el estadio menor, que es el cambio de un gobierno por otro; la segunda etapa de transición es cuando se hacen cambios en la parte política, económica y social, esa es la que hizo el gobierno de El Salvador, la transición salvadoreña esta ubicada en ese estadio; la tercera es el cambio de sistema, una transición de un sistema a otro, que fue lo que pasó en la Unión Soviética".

\section{ALFREDO FÉLIX CRISTIANI}

"Como desconocíamos las reales intensiones del FMLN, elucubramos que la reunión realizada en el balneario Oaxtepec de México, entre los partidos y el FMLN para discutir la propuesta de éste, que demandaba posponer las elecciones presidenciales de 1989 la realizaba el FMLN por razones tácticas, no porque tuviera realmente voluntad de negociación.

Digo esto porque inmediatamente que terminan las elecciones de marzo, una de las primeras cosas que hicimos, fue tratar de sondear que respuesta le daría el FMLN a un planteamiento nuestro, de esta naturaleza ya como gobierno, y aquí fue donde empezó cierta amistad con el padre Ellacuría. Le expresamos al padre Ellacuría y le explicamos cuál era el propósito nuestro, lo que queríamos proponer el 1 de junio. 
Lo hicimos, porque esto era tan importante para el país. Le dije a Ellacuría que yo no quería que se malograra, ni que fuera una idea al vacío y después quedar ya sin ningún elemento que ofrecer. La conclusión fue que el FMLN no tenía interés y el padre Ellacuría se sentía frustrado, porque él escuchó que el FMLN apostaba a una insurrección popular.

En aquel momento, después de nuestro triunfo electoral se venía diciendo que el FMLN había ayudado a ARENA a ganar las elecciones y si eso fue así, me imagino que el FMLN debe haber dicho: "Hombre, miren, Duarte está de capa caída, está criticado por todos lados, ARENA es la fuerza pero ARENA internacionalmente son los escuadrones de la muerte; fácilmente podemos generar rechazo en contra de un partido odioso, sangriento y de ese modo justificar una ofensiva".

Es decir, esa ofensiva no fue planificada entre julio y octubre de 1989, sino que desde antes; desconozco si eran todos los grupos dentro del FMLN que pensaban igual o no, el hecho es que a mi se me hace difícil pensar, de que existieron verdaderas intenciones de negociar de parte del FMLN, sino hasta después de la ofensiva de noviembre".

\section{MONSEÑOR GREGORIO ROSA CHÁVEZ}

"Hay tres elementos que añadir: primero, el papel del Comité
Permanente del Debate Nacional, que mantuvo en jaque a todos $y$ mantuvo el tema de la solución política en agenda; segundo desde el punto de vista de la iglesia, a nosotros nos ayudó muchísimo la famosa parábola de la casa en Ilamas, de Monseñor Rivera, para ver las prioridades y las metas: primero, hay que apagar el incendio; segundo, hay que rescatar a las víctimas; y tercero, hay que ver la forma de que el incendio no se repita. La aplicación de la parábola en la situación del país estaba muy clara; el incendio de la casa en Ilamas es el país en guerra, las víctimas son los huérfanos, las viudas, los desplazados, apagar el incendio significaba la solución política, y evitar que se repita el incendio es estructurar las causas que originaron el conflicto. Con este esquema él indicaba el camino que debería seguir la iglesia, esto fue muy importante; hay un tercer elemento y para aclararlo quiero contar dos anécdotas referidas al aspecto del contacto humano entre los actores y protagonistas del proceso de paz. En México, en septiembre de 1989, cuando por primera vez se reunieron las delegaciones del nuevo gobierno y del FMLN para abrir la negociación, dijo una comandante: "¿por qué no comemos juntos?". Esto es importante, porque marca el contexto de unidad; en La Palma, Chalatenango, en octubre de 1984, cuando Ilega Duarte y el Coronel Cienfuegos estaba como Ministro de Defensa, en un momento dado 
conversan los jefes militares de ambos bandos, este fue un momento clave.

Esto puso de manifiesto que la gente podía entenderse, comprenderse, que en el fondo todos éramos una misma familia y fue fácil entrar en ese calor humano que se dio en la última fase de la negociación. La dinámica de la guerra cambio en mucho cuando entró en el escenario el Comité Internacional de la Cruz Roja (CICR), una lógica distinta, la lógica de la humanización del conflicto, la lógica del derecho internacional humanitario. Recordemos que esto generó en el país un clima totalmente diferente cuando ya existía el canje e intercambio de prisioneros, de lisiados. Se adquirieron compromisos de respeto a los civiles.

Esto influyó en el conjunto porque la guerra afectaba a todos, recuerdo que en los primeros meses hubieron editoriales en los diarios del país que decían que la guerra no se podía humanizar, que era inhumana por naturaleza, era un rechazo a la visión internacional del derecho humanitario; sin embargo después habían grandes espacios informativos dedicados al efecto de humanizacíon de la guerra.

En ese sentido, los partidos políticos fueron descubriendo su papel y fueron sintiendo la presión de sus mismas bases para apoyar ese aspecto de la humanizacíon de la guerra. En esta línea se situó el hecho simbólico de Tenancingo el cual tuvo un gran valor pedagógico y ejemplar, costó montarlo, tanta lucha para conseguir el respeto de ambas fuerzas para la población civil. Esto demostró que sí se podía hacer del país un país en paz, si ambas partes cumplían los compromisos".

\section{NORMA GUEVARA}

"El surgimiento y pronunciamiento del Comité Permanente del Debate Nacional por la Paz, a favor de la solución política al conflicto fue una bandera levantada por muchos que eran parte del movimiento revolucionario y comprendían más directamente la tesis que ya existía en el FMLN de que "la negociación y la solución política negociada eran parte de una visión estratégi$\mathrm{ca}^{\prime \prime}$, como expresión de una maduración en las posiciones revolucionarias, de una visión mas integral del futuro, ya no sólo concretizado en el acto de vencer o ganar, sino qué hacer después de eso.

El giro concepcional de la Comandancia General del FMLN en 1985 y específicamente en el año 1987, permitió la actuación autónoma, inscrita en una solución nacional, popular y revolucionaria de la guerra, a otros actores sociales sin ser apéndices. Este giro de pensamiento tiene un alto sentido de visión del movimiento revolucionario que se expresó en todos los 
aspectos, incluso en la parte militar al capturar y respetar la vida de los prisioneros, cumplir los tratados internacionales de Derechos Humanos y exigir el cumplimiento de los mismos a la otra parte; todo lo que vino en relación a prisioneros y refugiados. Se abrió un espacio mental distinto, no creo que pudiera ser de otro modo o más revolucionario.

En Guatemala, la guerra no llegó a la capital, ni alteró la vida política, no vivieron la objetividad del conflicto, no llegaron a esas esferas; en cambio, en El Salvador el conflicto alteró todo. En Nicaragua los partidos que se quedaron estaban divididos, otros abandonaron la solución política. Entonces no podían a puro oxígeno volver fuerte a un débil Partido Demócrata Cristiano, porque por sí mismo no lo era.

En el país curiosamente las divisiones se dieron después de la firma de los Acuerdos de Paz, no se han perdido los perfiles de las instituciones políticas y sólo se están transformando en medio de un juego mas democrático".

\section{ARONETTE DÍAZ}

"Después de transcurridos varios años de guerra, no había claramente un vencedor ni un vencido y los esfuerzos internacionales presionaban más y más para la búsqueda de una negociación; a pesar que eran momentos difíciles de la guerra la apertura tenía que darse aún en contra de la voluntad de los que estaban en el gobierno en esa época por parte de la Democracia Cristiana y los mismos militares, porque era necesario establecer la búsqueda de la paz.

La actividad realizada por los partidos en ese rumbo me parece que es una de las etapas más importantes, porque permitió que enemigos que nunca se habían sentado en una mesa, pudieran iniciar en ese momento un acercamiento que Ilevara a buscar precisamente la paz.

Los que vivimos esa etapa estaremos de acuerdo en que contiene enseñanzas y experiencias que nos han marcado a todos a nivel individual; recuerdo que cuando nos juntamos por primera vez a finales de 1988, dirigentes de varios partidos en el Hotel Presidente en medio de la penumbre porque habían apagones de luz, en una esquina se sentó la gente de ARENA, que por cierto eran Alfredo Cristiani y Francisco Merino; también se sentaron Fidel Chávez Mena y Gerardo Le Chevalier por la Democracia Cristiana; Hugo Barrera del Partido Liberación; y en el otro extremo estábamos los de izquierda: por la alianza Convergencia Democrática, conformada por el Movimiento Social Cristiano, el Partido Social Demócrata y el Movimiento Nacional Revolucionario estaban Guillermo Ungo, Rubén Zamora y Mario Reni Roldán, yo estuve por el UDN. 
Esa misma distribución de las personas en ese momento se me ha quedado grabada para siempre; voces que reflejaban lo que estaba sucediendo, cómo las fuerzas políticas en ese país se comenzaban a encontrar y en lo que se refiere a las actitudes y reacciones de las personas también fue muy sintomática; había en el ambiente muchísima desconfianza, los saludos que nos dábamos eran fríos, formales y lo que se comenzó a debatir en la mesa de negociación sobre la contribución de los partidos políticos al proceso de paz, era escuchado con mucha incredulidad por todos, no era recibido amigablemente.

Lo maravilloso de todo esto es cómo posteriormente a partir de esas reuniones, las relaciones y las actitudes comenzaron a cambiar, los integrantes de los partidos llevaban cada vez más propuestas que pudieran ir ayudando en ese proceso, y el ambiente inicial que era muy tenso comenzó a ser de menor desconfianza, quizás no se había llegado todavía a relaciones propiamente amigables, pero pongámosle que iba en ese proceso, incluso comenzaron a generarse bromas entre unos y otros.

Todo ese ambiente ayudó al entendimiento y lo más impresionante de todo eso es que las personas que formamos parte de ese grupo, aún cuando sigamos teniendo posiciones ideológicas diferentes, hemos llegado a generar amistad, nos tene- mos respeto y al menos para mí, ha sido muy gratificante en determinado momento saber que con aquellas personas con las cuales teníamos clarísimas diferencias ideológicas que nos separaban y que era un abismo lo que había entre nosotros, desde entonces se siente un grado de acercamiento y sinceridad, que nos permiten intercambiar opiniones, buscar soluciones a problemas que uno u otro podemos confrontar y tenemos la confianza suficiente para llamarnos por teléfono o vernos personalmente y solicitar cooperación ante dificultades que uno u otro tenga.

Ese proceso que se vivió es importante y me parece muchísimo más importante que se conozca, porque lo lamentable es que no sea conocido por la mayoría de la gente todo lo que significó ese esfuerzo como una gran lección de entendimiento que debe rescatarse para que se convierta en enseñanza fundamenta para la población salvadoreña".

\section{SCHAFIK JORGE HANDAL}

"Para apaciguar los problemas en el Congreso crearon la Comisión Kissinger, de carácter bipartidista, la cual en su análisis en lo que se refiere al El Salvador, introdujo un par de novedades. Una de las que recuerdo, que es la más importante, es la siguiente: la Comisión Kissinger mantenía la tesis que para acabar con el conflicto en El Salvador, 
había que reactivar la economía sin parar la guerra y que la reactivación de la economía salvadoreña iba a conducir a reducir la fortaleza del FMLN; convirtiendo el problema del FMLN, en un problema de policía y que nosotros íbamos a ser aislados por la población, una vez que la población tuviera empleos y que se reactivara la economía.

Entonces no iban a ver presiones aquí a favor de la paz, porque no he mencionado las presiones que se dieron internamente, aquí para la paz; la iglesia estaba en la tónica de la declaración Franco Mexicana y jugaba el papel de intermediario; lo empezó a jugar en La Palma, lo siguió en Ayagualo y no le gustó el desenlace de esa reunión, y siguieron jugando ese papel, estaban por la paz, por la solución política negociada. Claro que en ese tiempo en el interior del país lo que se hacia era reprimir, tanta gente que capturaron, algunos que mataron por estar hablando a favor del dialogo-negociación.

Esa tesis era también respuesta a la tendencia que había surgido entre el empresariado nacional de buscar un entendimiento para reactivar la economía. La tesis nuestra sobre la reactivación de la economía era la siguiente: para reactivarla, se necesita ponerle fin al conflicto y para ponerle fin al conflicto se necesita una negociación, una solución política negociada. Además lo reforzábamos haciendo continuas propuestas que se la entregábamos a la iglesia, la iglesia se las llevaba al gobierno, le daba también información a las organizaciones empresariales y a otras organizaciones.

Nosotros alimentábamos la presión haciendo propuestas constantemente; desde 1981, nuestra tesis empezaba ya a tener cierto eco en el empresariado; mientras que la otra iba en detrimento porque sostenía que no se necesitaba terminar la guerra para reactivar la economía; "nosotros vamos a dar dinero para eso y de esa manera es que se va a derrotar al FMLN" argumentaban.

A partir de las recomendaciones de la Comisión Kissinger el volumen del financiamiento de Estados Unidos para El Salvador creció,, hubo varios años que anduvo alrededor de los 70 millones de dólares que incluía cooperación militar e inversión en la reactivación de la economía.

Nosotros decidimos, responder a esa estrategia con una línea permanente de sabotaje económico; fue entonces que sistematizamos el sabotaje a los tendidos eléctricos, que ya lo hacíamos pero no sistemáticamente y los paros del transporte, para hablar de dos líneas fundamentales de sabotaje que se convirtieron en líneas permanentes; lo cual va acompañado con la reiteración, en el plano políticodiplomático, de que era necesario una solución política-negociada para reactivar la economía. 
¿Qué otro resultado produjo? La corrupción del gobierno Demócrata Cristiano y del ejército, porque empezó a flotar una cantidad de dinero extraordinario que no se podía invertir productivamente pues no habían realmente condiciones favorables para invertir. Pero el gobierno empezó a repartir el dinero a través de los bancos nacionalizados, que con simples Ilamadas telefónicas, entregaron grandes cantidades de dinero; Duarte tenía problemas con los empresarios y creía que de esa manera los iba a tranquilizar y les entregó dinero, que los mismos sacaban fuera del país a depositar en bancos extranjeros.

Aquello trajo la corrupción en el gobierno y en el partido y las consecuencias todavía las estamos viendo; también produjo la corrupción de la jefatura militar; no de los que estaban en el campo, sino de los que estaban en los escritorios, de los jefes militares principalmente. Además, en el caso de los militares, ellos tenían acceso a los volúmenes enormes de dinero que circulaban para la guerra contra Nicaragua y se embarcaron en la aventura de enviar armas a la contra, utilizaron las instalaciones del aeropuerto militar de El Salvador para hacer esas operaciones y se metieron por esa vía al narcotráfico, se metieron en el negocio de la venta de armas por bastante tiempo hasta que la depuraron.

Todo esto le causó un daño muy grande a esa política, por eso andando algunos años los norteame- ricanos la empezaron a restringir, sin decir que la estaban cesando, sino que silenciosamente la fueron reduciendo

En 1989 llegó el gobierno de Bush quien tenía fama de ser un político más pragmático, que realmente iba a tratar de quitarse ese tema del conflicto salvadoreño; porque había que reconocer que el gobierno de Estados Unidos estaba comprometido en una estrategia global, que este iba a atenuar y a buscar solución al conflicto en El Salvador.

Teniendo en cuenta eso, el FMLN, ya no el FDR, lanzó una propuesta muy audaz y muy generosa el 20 de enero de 1989. Ese año iban a haber elecciones presidenciales en El Salvador. Propusimos postergar las elecciones por seis meses para podernos preparar y participar nosotros en esas elecciones, con el compromiso de que íbamos a respetar el resultado cualquiera que fuera y que además íbamos a reconocer como único ejército, al ejército del Estado y que nosotros nos íbamos a desarmar.

Si uno ve hacia atrás, ahí estuvimos en el filo de la navaja, pero hicimos esa propuesta demandando una serie de cosas: la autodepuración del Ejército con una comisión propia de militares y crear una institución, que todavía no le habíamos hallado nombre ni lugar, en el sistema jurídico nacional que defendiera los derechos humanos. 
En los partidos se debatió nuestra propuesta y aceptaron. En medio de todo aquello vino la gran vacilación. La primera reacción del Departamento de Estado del gobierno de Estados Unidos fue un poco elogiosa, cuidadosa, pero elogiosa, como abriéndole espacio; el Alto Mando de la Fuerza Armada salvadoreña dijo que no, que esa era línea del Pentágono y Duarte la vio también positivamente y parecía inclinarse a aceptarla; unos políticos proponían que hubiera una declaración de los tres Poderes del Estado, para abrir un espacio constitucional.

En fin, se debatía todo eso y los partidos se reunieron, ya tenían reuniones en la Interpartidaria; nosotros que supimos de esas reuniones decidimos invitarlos a un encuentro a discutir la propuesta y así fue que llegaron al balneario mexicano de Oaxtepec. El tema era si aceptaban o no esta propuesta, los partidos volvieron al país inclinados a favor de la propuesta, incluso la delegación de ARENA, pero el resto del COENA los paró en seco y los obligó a no hacer una nueva declaración; porque allá en México habían hecho declaraciones positivas a favor de las propuesta, incluso elogiosas para el FMLN.

Los norteamericanos cambiaron de opinión. Incluso el gobierno también lo hizo y nos mandó el mensaje de que no aceptaba la propuesta; Duarte estuvo todavía paliando. En un momento, hubo aquí una reunión de los Vicepresidentes de Centroamérica, en el Hotel Tesoro Beach de la Costa del Sol. El Alto Mando, temiendo que Duarte les hiciera una jugada si lograba un acuerdo de los Vicepresidentes, envió al General Vides Casanova al hotel mencionado, convocó a los periodistas en el lobby del mismo y mientras en otra sala estaban reunidos los Vicepresidentes, hizo una declaración tajante: "Si se aceptaba la propuesta del FMLN iba a haber golpe de estado por mandato constitucional, porque la Constitución decía que el Presidente que había terminado su período, no podía estar ni un minuto mas después de las doce de la noche del dia 1 de junio, que era el día debería entregar el mando presidencial".

A nosotros nos sorprendió cómo esta iniciativa terminó, luego tuvimos información bastante clara de que allá en Washington tanto la inteligencia militar, como el Pentágono, la CIA y el Consejo de Seguridad Nacional del gobierno, habían Ilegado a la conclusión en sus análisis de que esa propuesta tan blanda era expresión de debilidad, que eso tenía relación con los acontecimientos del Europa del Este cuya crisis ya se estaba precipitando incluyendo a la Unión Soviética. Como ellos seguían en la tesis que nosotros éramos un instrumento de la Unión Soviética, de Cuba y Nicaragua en el enfrentamiento de la guerra fría; consideraron que eso era lo que explicaba nuestra pro- 
puesta blanda y que por lo tanto no había que aceptarla, sino que alargar el tiempo porque ya la derrota nuestra estaba asegurada.

Frente a esa información es que la Comandancia General del FMLN tomó la decisión de preparar una gran ofensiva, y empezó a prepararse desde el mes de febrero de 1989, llegando a la conclusión de que ese discurso no podía ser rebatido con otro discurso, por eso preparamos la ofensiva que finalmente lanzamos en noviembre".

\section{ARMANDO CALDERON SOL}

"Atribuyo el éxito de la paz al cansancio existente en toda la sociedad salvadoreña; había una exigencia de todo el mundo por la paz y esto obligaba a todos los sectores a trabajar por ella. La mesa política abría el espacio para que la comisión negociadora tuviese un soporte de legitimidad, que no la tenía aún por no estar la representación de las fuerzas políticas. Era necesario crear esa mesa y que los partidos políticos dieran su aporte; así es como se forma esta mesa, que para mi es muy importante, a partir de ese momento es que se van esos viajes largos y se hacen las reuniones en México que dan muchos frutos.

ARENA pudo negociar porque existía un deseo por la paz y un cansancio por la guerra de parte de la población. Existía una disposición general favorable de parte de
Roberto D'aubuisson, quien era un hombre que tenía una visión política muy grande, y porque existía en ARENA también un cuestionamiento para lo militar. En ARENA existían los grupos que fueron afectados por la reforma agraria de 1980, y lucharon contra eso y de aquí nace ARENA. En ese período el ejército fue instrumentalizado para asaltar bancos, para asaltar propiedades y para romper la productividad del país. Creyéndose que con ese esquema los Estados Unidos rompía el esquema de la izquierda, y que aplicando esa lucha contrainsurgente, y haciendo una reforma agraria profunda, (que en efecto fue la mas grande de América Latina) y también una reforma financiera en la banca, (que nos lleva a los excesos de corrupción que nos llevaron) a la improductividad total en el agro hirieron sentimientos por el poder absoluto de los militares.

También con acciones aventureras como instrumentos de otros poderes para hacer lo que hicieron, porque nunca tuvieron el valor, ni lo hubieran tenido para hacerlo si no hubieran tenido el respaldo de los Estados Unidos, porque eso fue ordenado en la embajada americana. Habían ofendido y golpeado la fibra de algunos sectores económicos de El Salvador y esta es una realidad que todos la sabemos; ese militarismo que había golpeado, abusado y atropellado, tanto a la izquierda con la lucha contrainsurgente, golpeado los derechos 
humanos, etc., y a la derecha que la había robado y maltratado; se estaba viviendo esa lucha pero también existían esos sentimientos de insatisfacción y reclamo.

El ejército fue el gran factor que históricamente había venido detentando el poder, en abuso y había una conciencia clara que el poder absoluto corrompe absolutamente. En esto existía una conciencia generalizada entre los sectores intelectuales de derecha y de izquierda; entre los sectores sociales decentes, que no buscaban privilegios especiales o componendas, había también esa visión en conjunto que coincidía con la otra visión de la izquierda.

\section{El papel de la Asamblea Legislativa y de los partidos políticos}

Partiendo de que la conquista de la paz fue un esfuerzo colectivo, como pueblo y como nación y no de ninguna persona, sector o institución en particular; existe la necesidad histórica de hacer una investigación sistematizada sobre este importante capítulo de la vida de nuestro país. Desde esta perspectiva, el estudio que el lector tiene en sus manos, pretende introducirse en el ámbito de los partidos y de la Asamblea Legislativa, para explicitar su contribución al logro de la paz. Por ello hemos preguntado a nuestros entrevistados su opinión sobre el tema y ellos, han respondido con franqueza, a veces con elogios, pero también con críticas, sin dejar de mostrar su preocupación por el descrédito del sistema político salvadoreño.

\section{RUBÉN ZAMORA}

"Yo he escrito un trabajo sobre ese tema que se Ilama: Los partidos políticos: iinstrumentos $u$ obstáculos de la transición?, patrocinado por la Fundación Konrad Adenauer; en él planteo como hipótesis de trabajo, que el rol de los partidos políticos, en términos de pensar la transición como la introducción de una nueva cultura y una práctica que superara el autoritarismo, sustituyéndolo con la nueva cultura y la nueva practica democrática; yo veía el rol de los partidos políticos en una primera fase altamente positivo, porque en buena medida los partidos fueron portadores de la nueva cultura, creo que ahí el papel que jugó la Interpartidaria fue bien importante, las reuniones de Oaxtepec, fue preparando su participación, ya luego mas institucionalizada en COPAZ, y que se traslada todo ese rol después a la Asamblea Legislativa en la que estuvimos nosotros; fue en la Asamblea que creo se logra caracterizar por un nivel de construcción de consenso, yo diría extraordinariamente elevado para lo que ha sido la práctica del país. 
Sin embargo, veo un momento de quiebre hacia el año 94, donde la crisis de los partidos políticos o los elementos críticos al interior del partido político, hacen que los partidos, en vez de continuar jugando ese rol de portadores de la nueva cultura y la nueva practica, empiezan a ser reintroductores de viejas culturas y de las viejas prácticas no democráticas; los partidos abandonan esfuerzos de concertacion propiamente partidaria o lo que hacen no pasa de ser retórico; la Interpartidaria ya no se puede levantar. Se hacen intentos, pero fracasan; cuando se plantean esfuerzos de concertación nacional como el de la ANEP los partidos dicen si vamos pero no pasan a nada $y$, por otra parte, en la Asamblea Legislativa ya desde la legislatura pasada se ve una reintroducción de prácticas, dijéramos tradicionales de tipo impositivo.

Ahora bien, en la medida que el instrumento electoral se revaloriza los partidos políticos asumen una mayor cuota de poder; las reformas constitucionales también van orientadas a trasladar a los partidos políticos mayores cuotas de poder y en ese sentido creo que, conciente o inconcientemente, los partidos políticos empezaron, incluso antes de Chapultepec, a jugar espacios donde antes no jugaban, tanto de un lado como del otro, porque no sólo nosotros en la izquierda tomamos distancia del FMLN, sino que en el otro campo en donde estaban el PDC y el PCN, toman distancia del polo militar, del ejército, y empiezan a buscar sus propios juegos y propios espacios. Eso contribuyó a crear espacios comunes donde la parte fundamental estuvieron en contra de ella bajo colchones para encontrarse, pero yo creo que esa parte de los partidos era una clara expectativa que en la medida que se superara la guerra perdíamos los partidos las ataduras que nos tenían amarrados a los polos militares.

Es por eso que la crisis se hace todavía mas aguda porque les han dado mas responsabilidad a los partidos y estos no se han adaptado a la nueva situación; entonces se presenta el fenómeno de la disfuncionabilidad entre la responsabilidad que tienen los partidos y su forma de actuar; se vuelve mucho más evidente y lo estamos viendo ahora, la atomización de los que podrían estar en el centro que es mucho mas grande de lo que había hasta 1994; el centro se ha multiplicado en terminos de atomización en estos años; es evidente que ARENA tiene su crisis aunque no lo reconozca públicamente y del FMLN no se diga, o sea que en general existe en los partidos políticos una crísis reciente en su rol y representatividad".

\section{ANA GUADALUPE MARTÍNEZ}

"El origen de la Interpartidaria es en mayo de 1990, después de la firma del Protocolo de Ginebra, 
en abril de 1991. Alfredo Cristiani invita a los partidos políticos a una reunión en Casa Presidencial ofreciendo todas las facilidades del caso, dado el compromiso existente de ambas partes. No obstante, los partidos políticos, de una forma muy inteligente, adoptaron la decisión de no aceptar los ofrecimientos del Presidente. Dan las gracias por la iniciativa, pero consideran que deben estudiar la propuesta. Al final, deciden realizar las reuniones en la Asamblea Legislativa como un lugar neutral y aceptar únicamente las facilidades técnicas, es aquí en donde se plantea la necesidad de comunicación con el FMLN y se hace la reunión en Oaxtepec, México.

El gobierno no quería la participación de los partidos políticos porque podían hacerle coro al FMLN en algunas demandas, su preocupación era que el proceso se diluyera y lo llevará a una complejización del proceso y de los contenidos; el Frente lo que buscaba era hacer una correlación de planteamientos que tenía bastante claros y coincidentes con partidos como el PDC, PCN, UDN; teniendo sentido la preocupación del gobierno en ese momento, ya que el FMLN quería sociabilizar los contenidos de la negociación y convertirlos en mecanismos de presión al gobierno, para que este quedara aislado.

Era el juego de la correlación de fuerzas para una mesa de negociación que se empezaba a confi- gurar; el problema de la identidad, propia de los partidos, se creó a partir del intento de coptarlos a sus posiciones, porque lo que se quería era que sirvieran de colchón para las posiciones del FMLN en el debate con el gobierno y, básicamente el gobierno tenía la misma intención.

Ante esa realidad, los partidos previeron inteligentemente que era el momento de perfilarse con una acción totalmente independiente y posibilitadora, no polarizante; porque contaban con una madurez política. Tenemos el caso de Fidel Chávez Mena, Gerardo Lechevalier, el propio Hugo Barrera quienes vieron la oportunidad de jugar un papel de independencia.

Por otra parte, la Asamblea Legislativa no se podía modificar, era una Institución que constitucionalmente estaba registrada como lo es ahora y más bien la Asamblea va ir cambiando en la medida en que los partidos se vayan modernizando, lo que la hace una institución viva son los individuos con sus acciones políticas concretas que trabajan y mueven a la Asamblea y no la institución como tal con sus formulaciones administrativas.

En mi visión particular tenía la idea, cuando se formó COPAZ y que se detalló tanto sus funciones, que iba a ser la contraparte de verificación de los Acuerdos y terminó arrinconada con un cúmulo de actividades legislativas, con muy 
poca visibilidad en la población. Ya que la visibilidad completa la cubrió las Naciones Unidas, diluyéndose el papel de los políticos, de los partidos y de COPAZ misma; perdiéndose la parte nacional de verificación.

El otro elemento es cuando los partidos con representación en la Asamblea, que estaban en COPAZ, lograron hacer un ensamblaje armónico con la Asamblea, existiendo voluntad política, el sistema de partidos fue muy diluido en este proceso, las reformas legislativas fueron más un propósito de gobierno que del Órgano Legislativo y su partido tuvo mucho interés en dichas reformas".

\section{VÍCTOR MANUEL VALLE}

"Para la firma del Acta de Nueva York en septiembre de 1991, existía el interés de que los partidos asumieran un papel y surge la Comisión Nacional para la Consolidación de la Paz (COPAZ), donde se legítima y se le asigna un papel a los partidos políticos sin distinción de tamaño, reconociendo que hacía falta tomarlos en cuenta. Su anticipo fue que después de las primeras reuniones del Frente con el gobierno, básicamente desde el Acuerdo de Ginebra, le dan forma a la Interpartidaria que, junto al FMLN y el gobierno, forman posteriormente la COPAZ; pero ya COPAZ como parte de un compromiso y de un protagonismo que se le da a los partidos políticos.
Considero que el papel de los partidos políticos con todo y sus debilidades inherentes fue muy importante, no sólo por los acuerdos individuales que pudieron lograr los dirigentes, sino porque era una condición necesaria en vista de la evolución política que debía experimentar el país. El aporte de los partidos se da en torno a la negociación y después en la aplicación de los acuerdos; al establecerse la Fase Transitoria en COPAZ, los días 10 y 11 de octubre de 1991, en México, se legitima la Interpatidaria, pero además le da un papel importante a los partidos en la construcción de ese espacio de negociación.

Digo esto porque en COPAZ lo que hacíamos era discutir proyectos de ley, o sea la firma de los acuerdos desencadenaron una cantidad grande de leyes, que no se podían negociar en la Asamblea Legislativa, porque ésta tenía otra cosa, con otra dinámica y el Frente no podía entrar al país con su gente a negociar, porque todavía no estaban firmados los acuerdos. Es en la necesidad de que el Frente participara y de introducir proyectos de ley, en donde los partidos adquieren protagonismo, en esa fase de transición que hay entre el conflicto armado y la firma de los acuerdos.

Recuerdo muy bien que quienes concurrían a esa mesa en México, en el Salón del Automóvil, del Hotel Bristol, eran los dirigentes máximos de todos los partidos: Armando Calderón, Fidel Chávez, 
Rubén Zamora, Guillermo Guevara Lacayo, Mario Aguiñada. Creo que fue muy importante legitimar a los partidos, reconocerles su protagonismo y hacer que los partidos fueran productivos políticamente, y nada más productivo que preparar todo el andamiaje legislativo, ya aquí en el país.

En esta fase lo que faltó fue y eso fue bien obvio, lo vivimos todos, que los partidos políticos cuando la COPAZ se instaló en El Salvador, a partir del $1^{\circ}$ de febrero de 1992 le bajaron vapor; se veía que la gente ya no tenía tiempo de ir, ya no iba el dirigente máximo sino que iba otro. De todas maneras había explicación y hasta justificación, por ejemplo, Armando Calderón era alcalde y no podía estar en las reuniones de COPAZ y comenzó a mandar a Gloria Salguero, a Julio Gamero, a Raúl Somoza Alfaro.

Recordemos que ya en ese momento habían cambiado los conceptos de agrupamiento, porque cuando se establecen las comisiones de COPAZ, la gente creía que el FMLN, Convergencia, UDN y PDC eran un bloque y que el otro bloque estaba constituido por Gobierno, MAC, ARENA y PCN".

\section{MAURICIO DÍAZ BARRERA}

"En el movimiento revolucionario las ideas militaristas eran fuertes, si bien esas historias eran conocidas, los debates internos en el FMLN habían conducido a que los núcleos políticos que dirigían las organizaciones sociales y gremiales estaban prácticamente replegados y al servicio de las estructuras militares; el calificativo de político-militares que se atribuían las organizaciones que constituían el FMLN, era en la realidad una expresión falsa de la realidad interna organizativa y funcional de ellos, las cuales eran más militares que políticas.

El surgimiento del Partido Social Demócrata en 1986, es una iniciativa autónoma de quienes lo integraron. Se definió de izquierda y se inscribió legalmente y no fue sujeto de agresiones ni presiones; encabezaba ese movimiento el doctor Mario Reni Roldán, un hombre democrático sin antecedentes de militancia política y con muy buenas relaciones con los militares de aquella época, incluso algunos que ya no eran tan importantes pero seguían siendo gente influyente. En conjunto, el PSD era un grupo bastante complejo de gente que procedían del Partido de Acción Democrática, del Movimiento Nacional Revolucionario que se habían quedado en el país durante la guerra o habían regresado. Algunas personas procedían de grupos del PDC y probablemente había otros con afinidad al FMLN. Era una mezcla que comenzó a funcionar de esa manera, con todas las dificultades de un partido sin mucha cohesión orgánica, sin abundantes recursos económicos y funcionando 
en medio del temor a todo lo que pareciera izquierda.

Recién surgió el PSD trató de establecer contactos con la gente del Movimiento Nacional Revolucionario y del Movimiento Popular Social Cristiano (MPSC), a través de los referentes o delegados que tenían en el interior del país, y para conversar con las cúpulas salían al exterior cuando había oportunidad. De esa manera surgió la idea de la Convergencia Democrática en noviembre de 1987 en el exterior. El siguiente año regresó al país Rubén Zamora y el grupo de trabajo abierto que tenía el MPSC, de hecho ya tenían instaladas oficinas aquí en el país y habían comenzado el proceso de legalización del partido; más tarde regresó Guillermo Ungo.

En el año de 1988 hubo elecciones para concejos municipales y diputados, no recuerdo bien si había terminado el proceso de legalización el MPSC, creo que si hubiéramos tenido oportunidad de participar formalmente en dichas elecciones, pero las consideraciones fueron que no estaban muy claras las relaciones con los eventuales apoyos internos, la situación orgánica todavía era débil y lo de las finanzas estaba difícil, pero lo más importante fue que todavía no se habían terminado de separar aguas con el FMLN, lo cual ocurrió en el año de 1989 y a contrapelo de la opinión del FMLN de que la CD no debía participar en las elecciones presidenciales de ese año, sí participó la Convergencia Democrática. En este punto no vale la pena decir que el FMLN en términos generales estaba en contra, porque cualquier afirmación de este tipo había que relativizarla, dado que fue siempre una organización con diversas voces, que hablaba en diferentes tonos y con diferente énfasis; siempre fue interesante esa especie de múltiple personalidad del frente, todo lo cual atendía al hecho que estaba integrado por cinco organizaciones.

La campaña electoral de la CD en 1989 fue organizada muy apresuradamente, con pocos recursos técnicos, con un poco más de recurso material, pero todavía en la disyuntiva de que no era una alternativa de poder en ese momento, de hecho los resultados electorales arrojan un poquito más del $3 \%$ de la votación general para la Convergencia y obviamente obtuvimos pocos votos de la gente identificada con el FMLN, tanto por el desacuerdo oficial con nuestra decisión de participar en las elecciones, como porque la gente que era partidaria del FMLN ni siquiera podía votar, no estaban carnetizados, hecho que no se refiere únicamente a sus estructuras clandestinas e ilegales, sino a casi todos quienes no estaban listos para hacerlo porque no venían pensando en ello, ni siquiera se había registrado en el padrón electoral. 
Me interesa hacer referencia a la actividad de los partidos de izquierda en la segunda mitad de la década de los años 80, específicamente en 1986 y 1987; los partidos que no tenían la visión revolucionaria de la solución de la guerra adquirieron posibilidad de expresar sus puntos de vista como antes no había ocurrido, probablemente por dos razones básicas: uno, la situación de represión interna en el país había alcanzado grados de selectividad y de separación, la urbanización de la guerra, el hecho de que poco a poco se habían definido zonas de influencia y las ciudades estaban totalmente bajo el control del ejército, permitía jugar con cierta flexibilidad a grupos que no levantaban la bandera revolucionaria; y dos, que los partidos de izquierda resurgen sin ser amenaza electoral y las elecciones de 1989 lo demuestran, es decir legal y electoralmente estos partidos no resurgen con una fuerza suficiente para ser alternativas que amenace las estructuras de poder establecidas y sin embargo aportan al esquema político que todavía es contrainsurgente, el componente de aislar del FMLN a fuerzas que entonces nos llamábamos democráticas.

Eso se fue asentuando en la medida que la Convergencia planteaba como uno de sus puntos principales la solución política negociada al conflicto y al final la convirtió en consigna de campaña electoral; mas tarde lo hará la UDN con los mismos planteamientos, de manera que eso les permite a estos partidos adquirir una cierta personalidad propia. En el caso del MNR y del MPSC, era mucho más difícil, porque ellos habían sido incluso parte del FDR, o sea, de los aliados estratégicos del FMLN en la primera mitad de la década de los años 80. Para el PSD era mucho mas fácil, en términos de imagen y de manejo interno, porque no significaba desligarse de nada, nunca fue una organización de esa agrupación, aunque ello le implicaba debilidades, porque no tenía ni las relaciones, ni los recursos, ni el fogueo en el manejo de la relación internacional, tampoco disponía de recursos materiales y financieros, ni de cuadros experimentados; era, en suma, un partido bastante débil.

En resumen, el cambio que se produce en el ámbito de la izquierda es que primero retornan sus dirigentes principales y se legalizan en el año 88/87; luego aparecen en medios de prensa y están en el entorno político, y se sabe que están allí y que se mueven, ya son legales, y en el año 89 participamos en las elecciones. Ya estaba la izquierda armada, la izquierda revolucionaria, que no dejaba de considerar el acto de regresar a la legalidad tanto del MPSC, como del MNR, del PSD y del UDN, como un acto que lesionaba sus intereses, y es que de hecho se dividía el gran bloque democrático-revolucionario, pero eso es lo que precisamente se había roto. 
La instalación de la Interpartidaria es muy importante, se da en el período posterior a la ofensiva del año 89, ella promueve el sistema político y hace más clara la disyuntiva: o se negocia o se producen ofensivas de aniquilamiento; los grupos de poder más importantes y la presión internacional especialmente la norteamericana, empujan a que los partidos empiecen a hablar en un entorno donde todos puedan dialogar de igual a igual. Ese entorno es la Interpartidaria, que fue capaz de convertirse en el foro donde se formalizaban los planteamientos, se afinaban y se discutían y al final servía para impulsar el proceso de negociación que cursaba por una vía paralela pero que estaban conectadas.

Hubo momentos importantes en la Interpartidaria, cuando por las torpezas que a veces cometía gente del FMLN, como en el tema de los secuestros y en todo eso, la Interpartidaria funcionaba como una especie de llave maestra que desentrampaba el cerrojo mal puesto. Aparte de la mesa de negociaciones formal, la de poder, donde se estaban cruzando las fuerzas beligerantes, había observadores interesados, no sólo por sus cuentas estaban siendo revisadas en la Interpartidaria. En la última fase de la negociación la Interpartidaria, poquito a poco, se fue convirtiendo en algo que después se Ilamó COPAZ, va abriendo cada vez mas espacios, de manera que se podía incidir en decisiones políticas que tomaba el gobierno de Cristiani, las que pasaban previamente por decisiones partidarias".

\section{SCHAFIK JORGE HANDAL}

"A partir de la reunión de Oaxtepec en enero de 1989, se abrieron contactos por supuesto entre el FMLN y los partidos, pero estos ya no volvieron a tener durante todo ese período un papel directo, activo, que yo recuerde; a lo mejor no recuerdo algunos hechos.

Los partidos volvieron a tener participación cuando se inicia la negociación, porque en el acuerdo marco, que fue el Acuerdo de Ginebra de abril de 1990, nosotros logramos que se incluyera un párrafo en el que se legitimaba los contactos de cada una de las partes con las organizaciones sociales, religiosas y los partidos. Se establecía la eventual posibilidad de que estas organizaciones y estos partidos pudieran sentarse en la mesa de negociaciones junto con las partes; lo cual nunca llegó a ocurrir porque siempre en momentos en que fue conveniente y nosotros lo propusimos el gobierno se negó, y es que ese párrafo decía que debía haber acuerdo de las dos partes.

Entonces los partidos llegaban a reunirse con nosotros después de cada ronda de negociación, también llegaban organizaciones sociales y escuchaban nuestro 
informe y luego nos pedían sesiones bilaterales. Los primeros que nos pedían bilaterales eran los de ARENA. Entonces, la información de la que disponían prácticamente era la nuestra, porque el gobierno a su propio partido le daba una información muy general, no le explicaba cuáles eran las cosas que se habían discutido en la ronda de negociación, nada de eso.

En las reformas a la Constitución se concretó el nudo principal de la reforma militar, puesto que ahí se modificaron las atribuciones y las misiones constitucionales de la Fuerza Armada. Ahí nosotros también hicimos el giro que habíamos previsto, de no insistir en la desaparición de esa institución. Paralelamente a eso ocurrió un hecho que no puedo ubicar en el tiempo exactamente, y que consistió en lo siguiente: Cristiani invitó a dirigentes políticos, especialmente a Rubén Zamora, Ungo, Guillermo Ungo, Fidel Chávez y Armando Calderón Sol, para proponerles firmar un documento sobre Fuerza Armada, con el propósito de que ese fuera el documento que influyera en la mesa a la hora de terminar de negociar este tema; y ese documento distraía de las cuestiones medulares contenidas en el planteamiento del FMLN, le quitaba profundidad a las reformas y en ciertas medidas volvía a los conceptos de un documento presentado por el Gobierno en octubre de 1989, en San José, titulado "El papel de la Fuerza Armada en una sociedad democrática". No era exactamente el mismo documento, estaba reelaborado sobre la misma base y camino. Era una maniobra de utilización de los partidos políticos para atajar o comprimir el planteamiento del FMLN sobre Fuerza Armada.

Nosotros nos enteramos de eso por Guillermo Ungo. Él fue a México, nos buscó y nos dijo: "miren, lo que está pasando" es esto y nos entregó copia del documento; Rubén Zamora no dio ninguna señal, él estaba completamente involucrado y de acuerdo con esa posición. Entonces, decidimos abortar esa maniobra filtrando el documento a la prensa y haciendo declaraciones públicas de que eso era inaceptable, dijimos que era una maniobra, la denunciamos y ahí terminó, ya no apareció en la mesa, el documento ya no lo firmaron los dirigentes de esos partidos.

\section{GERSON MARTÍNEZ}

"El papel del FMLN, probablemente a diferencia de otros actores, no puede verse solo a partir de los Acuerdos de Paz sino que tiene que verse casi en el mismo estallido de la guerra; por esas circunstancias de la guerra y la vida la Dirección del FMLN para la primera ofensiva, que marca el inicio de la guerra civil, tiene que salir al exterior, desde mi perspectiva, creo que tanto la DRU como el resto de la dirección ya tenía una noción muy primitiva, 
del componente diplomático y del componente político del conflicto y de la solución del mismo, pero esas circunstancias de que la Dirección se traslade al exterior le comienza, diría yo, a condicionar, al punto que en mayo de 1981, se presenta la primera iniciativa de paz en la ONU del FMLN/FDR, a través del Presidente de Nicaragua. Esto es importante, porque, ¿cómo se explica que un movimiento que se ha enfrascado recientemente en un proceso armado presenta una propuesta?, ¿qué significado tiene? Yo diría que fue una iniciativa de paz con fe en la guerra, o sea la iniciativa de paz en ese momento es una señal mas de voluntad de negociación que de voluntad real de negociación, en ese momento el FMLN había entrado con fuerza a disputar la iniciativa internacional y diplomática. O sea que la noción primaria de negociación del FMLN tiene un componente más diplomático que de política interna, estando muy motivados. Por eso, considero que fue una iniciativa de paz de carácter diplomática con fe en la victoria militar.

La otra parte también tenía fe en la guerra pero ni siquiera había visionado el componente de la solución política. Eso iba a marcar en los siete o diez años posteriores una diferencia que el FMLN estaría adelante en el terreno diplomático y en el de la negociación, en todo ese período subsiguiente que es un período de guerra con el diálogo, en el que éste sería un elemento accesorio, más bien oxigenante. Este período se extendió hasta por los años 87, durante el cual la opción era la solución militar con un componente muy accesorio de solución política, o sea lo militar determinaba lo político y lo diplomático, pero había sucedido una cosa que cambiaba todo cada vez más lo diplomático y lo político influía en la conducta militar; creo que hasta por los años 87-88 lo militar era lo sobre determinante, aún cuando lo político negociador va creciendo en peso y por momentos tiende a disputarle la influencia, lo voy a decir en buen cristiano, las decisiones que se tomaban en la Comandancia General con el grupo negociador de la Comisión Política Diplomática (CPD), modulaba muchas veces la conducta militar, detenía ofensivas, comienza a determinar las formas de acción, lo que se vale, lo que no se vale, como hacerlo, o sea no era estático, poco a poco va ganando mas peso, lo político sobre lo militar.

Por eso, creo que ya desde el año 88 en el FMLN comienza a darse, tanto adentro como afuera del país, una reflexión y a veces un debate interno sobre la apuesta a la solución militar o a la solución política negociada, quiere decir que la opción por la solución política negociada vino ganando más peso en el FMLN. Cada vez había más comprensión, más conciencia y adquiría más incidencia en las decisiones y comenzamos a ver una Comandancia General más política, 
más diplomática y menos militar, aunque también en los últimos años había momentos en que parecía más militar que político/diplomática, pero el componente diplomático vino jugando un papel cada vez más de mayor peso.

Ahora, el FMLN nunca tuvo la idea de manipular a los partidos. Es más, no teníamos en ese momento los mecanismos para hacerlo. Más bien, creo que sí fue una actitud del FMLN bastante abierta de tomar en cuenta los distintos sectores de la vida civil, que inclúa a los partidos políticos con la esperanza de que los políticos, por ser civiles, podían entender mucho más la solución política negociada y ayudar a que incluso los mandos militares lo asimilaran. Se aspiraba a que estos sectores apoyaran la reforma democratizadora y la apertura.

Sobre las razones que tuvieron los partidos para apoyar el proceso de paz no tiene una respuesta simple; primer elemento de contexto, ya se había sedimentado en el país un consenso mayoritario, no general, no total, en favor de la solución política negociada, a esas alturas la mayor parte de la gente se pronunciaba mas por ponerle fin a la guerra que por apoyar la guerra; segundo, creo que hubo dirigentes en los partidos que percibieron que la solución política negociada era inevitable, que era una nueva realidad; tercero, que los partidos se percataron que otros actores de la sociedad, ya estaban participando en el diálogo: empresarios grandes, medianos y pequeños, sectores laborales, de iglesia, incluso otros actores internacionales diplomáticos, países amigos, todo ello condicionó la actitud de los partidos".

\section{MIGUEL SÁENZ VARELA}

"La participación de los partidos políticos fue bastante racional, si tuvieron participación desde el principio pero no fue de mutuo acuerdo, mas tarde se dejó al partido de gobierno y al FMLN que eran los partidos políticos que participaron directamente en la negociación durante todo el proceso; pero poco a poco los demás partidos se involucraron de manera importante, sobre todo desde la Interpartidaria, empezaron a tener una incidencia bien fuerte, actuaban organizadamente y elaborando ciertas propuestas que en determinados momentos ayudaron a desentrampar situaciones que estaban detenidas en la mesa de la negociación y contribuyeron en ese sentido. En ese tiempo tuvieron una participación al principio muy débil pero efectivamente importante, aunque personalmente creo que en ningún momento de la negociación tuvieron una participación decisiva en la negociación.

Una vez firmados los Acuerdos de Paz, los partidos políticos, a través de COPAZ, hicieron un esfuerzo muy grande y fructífero, todo en la primera fase transitoria de CO- 
PAZ, que le llamábamos en el exilio cuando nos reuníamos en México; fue una etapa muy importante, de mucha propuesta, de mucha participación de los partidos políticos. Posteriormente cuando se firman los Acuerdos de Paz el 16 de enero de 1992 y se instala COPAZ ya aquí en San Salvador creo que poco a poco se fue disminuyendo el papel de los partidos y ARENA logró aglutinarse con el PCN y el PDC a sus posiciones, principalmente al PDC.

Al interior del FMLN en aquel momento había mucha desconfian- za de la participación de los partidos políticos, por la trayectoria de algunos como el PDC y el PCN, el PDC participó en la etapa mas dura, mas cruel de la guerra, hizo pacto con el ejército, incluso hubo cierto grado de oposición por la participación del PDC y del PCN, teníamos razón de sentir desconfianza; posteriormente se entendió que no se podía ni se debían excluir a nadie políticamente eso era un absurdo y no podía ser así. Lo que se debía hacer era establecer relaciones sobre la base concreta del desarrollo de su participación".

\section{La sociedad civil empujó hacia la paz}

La Ilamada sociedad civil, estuvo presente durante la guerra como víctima, pero en la búsqueda de la paz lo hizo como sujeto activo, habiendo contribuido con propuestas, iniciativas y acción de masas persistente, hasta que fue escuchada. Del cansancio se pasó a la acción. Así creció entre los dos bandos en pugna, una enorme franja de salvadoreños que desestimó la vía militar y se pronunció por la solución política al conflicto; la concurrencia a las elecciones durante toda la década de los años ochenta fue una expresión clave de que el pueblo prefería apostar a la paz y a la democracia. Por eso es que todos nos unimos alrededor de los Acuerdos de Paz, que vino a ser la agenda transformadora de todos los salvadoreños.

\section{DAGOBERTO GUTIÉRREZ}

"Durante el período de aplicación de los acuerdos, es importante apuntarlo, para la sociedad salvadoreña no fueron nunca disputa, ni fueron nunca motivo de pelea, ni de movilización en la relación entre la aplicación de los acuerdos y la lucha por la vida; la sociedad salvadoreña apostó siempre a la lucha por la vida y lo relacionado con los acuerdos se dio como un negocio particular entre el FMLN y el gobierno en el que nadie se metió; por cierto que para meterse debía de tenerse bastante fuerza, por lo menos la fuerza necesaria para ser parte interlocutora de eso, pero siempre el factor decisivo estuvo expresado en las dos partes; la aplicación de los acuerdos no fue nunca, me parece 
a mí, una motivación social, factor de luchas sociales y ahí de nuevo los partidos políticos no jugaron un papel decisivo, toda vez que el pensamiento central fue, y creo que lo sigue siendo, de que ese era un negocio del FMLN y del gobierno".

\section{OVIDIO HERNÁNDEZ}

"No es menos cierto que el pueblo salvadoreño jugó quizás el papel principal porque fue tolerante hacia los dos bandos durante el conflicto, se encontraba en el medio, especialmente las comunidades donde se dio el conflicto y que sufrían constantemente en el cambio de manos de ese territorio, a veces dominaba el Ejército y otras veces la guerrilla; la comunidad era afectada y tenía que estar guardando un equilibrio entre los dos bandos porque en los pueblos que los tomaba uno y otro, el que lo tomaba en cada ocasión, les echaba en cara que habían estado apoyando al grupo anterior y este era un problema para la población y no en pocos casos hubieron revanchismos motivados por esa situación inestable.

En esa disputa entre los bandos en guerra, quizás a la conclusión de que se "dieran en la madre" entre ellos, mientras él se quedaba en espera haber qué pasaba porque no podía estar optando por uno u otro en esta situación; sin embargo, ya en la gestación de los acuerdos de paz el pueblo tuvo un apoyo decidido a esos acuerdos, tanto cuando se produjeron como cuando se aplicaron produjeron, porque realmente estaba cansado de esa guerra en la que se consideraba representado por ninguno de los bandos aunque ambos le decían que era por guardar sus intereses o por propiciar condiciones mejores de vida".

\section{RICARDO PERDOMO}

"Hay un hecho anecdótico de una reunión de la Interpartidaria en México, donde Schafik regañó en el hotel a todos los representantes de los partidos políticos. Entonces, me levanté a reclamarle por qué nos estaba regañando, que por qué nos estaba viendo de menos y ahí nos dimos cuenta que los grandes actores querían ver de menos el papel de los partidos políticos, pero cuando se dieron cuenta que los partidos políticos eran los que permitían que una idea cuajara, madurara, se empezó a adquirir un mayor respeto y valor al papel de los partidos políticos; tanto fue así que por la noche hubo una reunión entre la dirigencia de la Democracia Cristiana y los Comandantes en mi habitación en el hotel, y uno de los temas centrales que ahí se discutió fue precisamente algo tan delicado que era el desarme y el rol de las Fuerzas Armadas, le dedicaron tiempo se hicieron discusiones de profundidad.

Con este ejemplo, quiero decir que fue evolucionando el papel de los partidos políticos, de simples 
espectadores y de acompañantes a co-protagonistas, y creo que surgieron de documentos y de propuestas que eran más vendibles; pero cuando los partidos políticos planteaban cosas como por ejemplo al sector empresarial, cuando los partidos políticos planteaban cosas a ciertos sectores que no tenían un puesto en la mesa, como que logró hacer participar y convencer a mucha gente de la conveniencia y la necesidad de los Acuerdos".

\section{JORGE ZEDÁN}

"Mi línea de comunicación en el Canal es muy independiente no acepto sobornos, no acepto que alguien me diga te voy a dar publicidad pero ayúdanos, no, no, mi línea ha sido la misma porque he visto el proceso político desde el año 60, tengo ya practicamente 40 años de ver el proceso de mi país y por eso mantuve mi independencia y por eso Canal 12 va a ser recordado en la historia de este país cuando se escriba, de que realmente rompió los patrones, aunque no lo digan otros en un $100 \%$; pero no es un mérito de Jorge Zedán, es un mérito de un equipo de trabajo.

Quiero contar esta anécdota que es muy interesante. Cuando en Nueva York nos entregaron el Premio María Cabot en 1994 del Empresario Distinguido de las Comunicaciones, y le preguntaron a Mauricio Funes en el New York Times, ¿cómo era posible que en ese tiempo de la guerra el dueño de un canal de televisión y él como periodista, pudieron lograr esa unión?; Mauricio respondió, porque generalmente el medio va por un lado y el periodista va por otro lado.

Para nosotros ha sido fácil porque el dueño de Canal 12 tiene vocación democrática y el periodista tiene vocación democrática, entonces no hubo problema; porque no entendían cómo el dueño sacrificaba su dinero para tener un medio independiente que es difícil querer tener un medio independiente donde todo se maneja con publicidad.

El premio María Cabot se otorga entre 1700 medios de comunicación; y no se dijo mucho aquí porque era un premio de Canal 12, pero por primera vez en la historia que lo obtiene un canal de televisión; el María Cabot es un Premio Nóbel de Periodismo.

Otra anécdota: entre septiembre y octubre de 1989, Narciso Castillo, que era nuestro Director de Prensa, me dijo un lunes: "por primera vez el Presidente Cristiani ha aceptado venir el viernes a una entrevista". Y nos preparamos para recibirlo. El jueves, a las 4:00 de la tarde, Ilega Nacho Castillo a mi oficina y me dice, muy enojado: "Don Jorge, me han cancelado la entrevista de mañana, el Presidente Cristiani va a estar en TCS". Y le digo: "¿qué tienes grabado?". "Una 
entrevista de Schafik Handal en Costa Rica de una hora". Le respondí: "Ponela mañana". Y esa fue la primera vez que Schafik Handal apareció en televisión. En la encuesta, 95 personas estaban viendo a Schafik Handal por curiosidad o

NOTA

1 Por razones de espacio, en esta publicación incluimos una selección de las entrevistas correspondientes a los primeros cuatro temas. N. del E. por lo que sea, y 5 estaban viendo a Cristiani; y, ¿sabe lo que hizo el gobierno?. El domingo nos obligaron, a punta de pistola, a poner la entrevista de Cristiani en TCS. Eso es lo que pasaba hace diez años". 